\title{
The Construction of Personal Learning Networks to Support Non-Formal Workplace Learning of Training Professionals
}

\author{
http://dx.doi.org/10.3991/ijac.v8i2.4367 \\ C.A. Manning, PhD \\ Lesley University, Cambridge, MA
}

\begin{abstract}
Workers in the $21^{\text {st }}$ century workplace are faced with rapid and constant developments that place a heavy demand on them to continually learn beyond what the Human Resources and Training groups can meet. As a consequence, professionals must rely on non-formal learning approaches through the development of a personal learning network to keep up-to-date. This phenomenological study used an explanatory mixed methods approach to examine the lived experiences of how training professionals construct their personal learning networks to support their continuous learning in the workplace.
\end{abstract}

Results from this study indicate that participants have integrated non-formal learning into their work stream with a majority spending between one to three hours per week on these types of activities. This study uncovered two primary reasons for continuous learning: keeping up with industry trends and project-focused learning. Some significant differences in personal learning network construction were found based on gender, age, experience, and education.

Examining how training professionals use various approaches for their own non-formal learning serves to provide guidance to both individual and organizational learning strategies that need to leverage limited resources and organizational expertise while meeting the rapid and constant changes of the $21^{\text {st }}$ century worker.

Index Terms-non-formal learning, personal learning networks, PLNs, connectivism

\section{INTRODUCTION}

Workers in the $21^{\text {st }}$ century workplace are faced with a rapidly changing environment to which they must quickly adapt [1]. These rapid and constant developments place a heavy demand on employees to continually learn [2]. Corporations have traditionally relied on the Human Resources and Training groups to ensure employees have the education and training they need to be successful. These groups invest in developing and delivering formal training programs for employees based on needs assessments and management directives. In the 2012 State of the Industry Report, the American Society for Training and Development (ASTD) estimated that US corporations spent approximately $\$ 156.2$ billion on formal training and development programs for their employees [3]. However, due to the fast pace at which business is conducted, employees often do not have time during their normal business hours for formal programs and seek non-formal learning as a supplement or replacement [1]. In fact, $83 \%$ of surveyed corporations reported that non-formal learning is occurring to a moderate to extremely high degree [1]. Further, these same surveyed corporations indicate that they expect the use of non-formal learning to increase by $56 \%$ over the next three years [1]. This indicates that, while employers do provide formal training, employees cannot and do not rely solely on them to learn everything that they need to know for their job [2]. Instead, they must supplement formal programs with non-formal learning that is often completed on their own time [2]. It is this non-formal learning that is the focus of this research study.

With the rapid pace of new knowledge creation and the inability of formal training programs to address all of their required workplace learning needs, professionals must rely on non-formal learning approaches to keep abreast of new developments in their field. The development of a personal learning network [4] provides the connections to people and information that support non-formal learning.

The issues related to the increasing speed of change and knowledge creation also affect how Training and Human Resources provide learning in the organization. It is increasingly more challenging for the Training organization to keep up with the fast pace of knowledge creation in the workplace through the delivery of formal training programs. The cost of designing and delivering formal training programs as well as the cost of removing the employee from the work place in order to attend a training course that only meets at most $20 \%$ of the worker's learning needs have given rise to an increase in interest in a new and better solution. Instead of focusing on traditional behaviorist or constructivist-oriented instructional design models, these groups should consider incorporating more of the connectivist theory into their instructional designs. Connectivism includes some important aspects of andragogy such as the assumption that the adult learner is has the ability and self-motivation to control their own learning [5].

Connectivist learning theory re-defines learning and knowledge creation as connecting to information located in other people and appliances such as computers and databases. The assumption in connectivism is that the climate, characteristics, and flow of knowledge have changed [6] as a result of the creation of an increasingly large amount available information and the ease of access to this information. Connectivism shifts the focus from knowledge accumulation to the creation and preservation of connections to information sources [7].

Connectivism is based on the idea that most learning is self-organized (non-formal) and that the most significant 
skills we possess are acquired through trial, error, and experimentation [6]. It is the sharing of information and experience with each other in a learning community that (Stephenson as cited by Siemens) is the best teacher of knowledge. Since we cannot expect to experience everything that there is to learn ourselves, we must rely on the experiences of other people as a surrogate for knowledge [8]. It is these connections to people and appliances that form the foundation of Connectionism.

As a means to connecting to people and information, each individual creates a personal learning network (PLN). A PLN consists of a collection of resources or nodes (people, content sources, etc.) that an individual accesses as needed for his or her learning [9]. A PLN can consist of people such as friends, family, colleagues, former teachers or students, and other individuals who are knowledgeable about a subject; and things such as books, professional journals, professional organizations, professional conferences, blogs, and online communities like LinkedIn, and Twitter feeds [9, 10]. Every PLN is built individually through the person's individual learning needs using her or his own knowledge of the subject and connections. It is driven entirely by the individual's interests and provides access to information as needed [9](Bauer, 2010).

In the $21^{\text {st }}$ century workplace, knowledge is less something that resides in the individual and more something that is distributed throughout a network [11]. As a result, the development and maintenance of high quality of network connections is critical. Human Resources and Training groups should be moving toward shifting workplace learning away from solely formal training programs to becoming a learning organization where learning is embedded in the work processes [12]. Creating a learning culture in the organization has a strongly positive relationship with integrating new technological advances into the daily work activities [13]. Employees working in organizations that encourage personal learning (non-formal) become better able to adapt to the constant changes and demands made on them in the workplace [14].

This study focused on understanding how professionals construct their personal learning networks (PLN) to support the non-employer provided or mandated learning that they need for the workplace. To better understand what is currently happening, this study focused on investigating the following five research questions to better understand the participants' experience:

1. What factors influence the choices that training professionals (the participants) make in constructing their personal learning networks to support their nonformal workplace learning needs?

2. To what extent do they report incorporating Twitter, blogs, webinars, and social media technologies as a means of connecting with other practitioners to share information? To what extent do gender, age, education levels, and experience levels impact this component of their PLNs?

3. To what extent do they report incorporating personal contact, professional organizations, and conference attendance as a means of connecting with other practitioners to share information? To what extent do gender, age, education levels, and experience levels impact this component of their PLNs?
4. To what extent do they report incorporating other technological and non-technological means to locate professionally relevant information? To what extent do gender, age, education levels, and experience levels impact this component of their PLNs?

5. What criteria do they use to determine expertise (trusted sources) especially as it relates to reaching out to others for advice? To what extent do gender, age, education levels, and experience levels impact their decisions about experts for inclusion in their PLN?

\section{RESEARCH MEthods AND PROCEDURES}

\section{A. Design and Approach}

This study examined the shared experience of training professionals in developing a personal learning network for their continuous, non-formal learning. The selection of this population was in part as a result of the researcher's familiarity with the population through direct experience as a member of the profession. It was also due to the nature of the profession that is focused on helping others to learn and on how best to organize learning for their target audiences. As a result, this population would be most in tune with how learning in the organization was happening and what initiatives were in progress to support formal and non-formal learning.

In order to examine this shared experience, the researcher selected phenomenology as the most appropriate research methodology for data collection and analysis. While phenomenological studies usually take the form of interviews consisting of a small number of open-ended questions, this study instead used a sequential explanatory mixed methods approach that supported the researcher's pragmatic worldview. Starting with quantitative data and then gathering more detailed and rich qualitative data provided the researcher with two forms of data that could be used in combination that helped to provide a broader view of the phenomenon thus allowing for a deeper understanding of the findings [15] than .

The combination of both quantitative and qualitative data served to provide a better understanding of the research problem and questions [16]. In the first part of the data gathering, the researcher collected responses to a set of survey questions [15]. The quantitative data collection provided the researcher with the ability to discover trends [16] that was then further explored in the qualitative interviews. In the second phase of the study, the researcher interviewed a purposeful selection of participants from the survey respondents. The researcher used these interviews to collect more detailed information about the quantitative data that could only come from asking open-ended questions that allowed the participant to give detailed descriptions.. The combination of the two types of data created a robust view of the phenomenon under examination.

\section{B. Participants}

The participants for this study were Human Resource and Training professionals responsible for coordinating learning for the employees in corporations including people who identified their primary job roles as a Trainer, Course Developer, or Instructional Designer. Training and Human Resources are the groups within companies whose primary mission is to help the other workers stay current with the new trends and information that is related to their 
respective roles. In many cases, these groups are also responsible for helping workers to gain the knowledge and skills to move from one position to another. Because they have chosen this field, they are focused on helping others to learn and on how best to organize learning for their target audiences.

In the first phase of the study, participants were located using three different methods. First, participants were solicited from local chapter meetings of the International Society for Performance Improvement (ISPI) and the American Society for Training and Development (ASTD). Second, a post was placed on several LinkedIn groups that are commonly used for sharing best practices among Training Professionals. Finally, the researcher attended two conferences in 2012 to solicit participants. The first conference was the Performance Support Symposium, in Boston and the second was DevLearn in Las Vegas.

The target number for survey participation was 100 participants. The actual number of participants who responded to the survey was 124 . Table 1 lists the demographic breakdowns for the participants.

TABLE I.

PARTICIPANT DEMOGRAPHICS

\begin{tabular}{|c|c|c|}
\hline & Responses & Percent \\
\hline Gender & & \\
\hline Female & 80 & 65 \\
\hline Male & 39 & 31 \\
\hline No response & 5 & 4 \\
\hline $21-29$ & & 2 \\
\hline $30-39$ & 2 & 23 \\
\hline $40-49$ & 29 & 29 \\
\hline $50-59$ & 36 & 35 \\
\hline $60+$ & 43 & 6 \\
\hline No response & 8 & 5 \\
\hline Associates & 6 & 3 \\
\hline Certificate & & 10 \\
\hline Bachelor's & 13 & 32 \\
\hline Master's & 40 & 44 \\
\hline Doctorate & 54 & 6 \\
\hline No response & 7 & 5 \\
\hline & 6 & \\
\hline
\end{tabular}

The second data collection phase used a purposeful selection of participants from the survey results. Polkinghorne (as cited in [17]) recommends that between five and 25 participants who have all experienced the phenomenon be interviewed. For this study, a total of 17 interviews were conducted. Five participants were selected in each of the experience categories of entry-level, mid-career, and senior-level professionals. These participants were also grouped based on their formal education levels of Bachelors, Masters, and Doctorate. Additional participants were selected to ensure that at least five participants for each of the education levels.

\section{FINDINGS}

This study focused on investigating the following five research questions that were relevant to gaining a better understanding the participants' experience:

1. What factors influence the choices that training professionals (the participants) make in constructing their personal learning networks to support their nonformal workplace learning needs?
2. To what extent do they report incorporating Twitter, blogs, webinars, and social media technologies as a means of connecting with other practitioners to share information? To what extent do gender, age, education levels, and experience levels impact this component of their PLNs?

3. To what extent do they report incorporating personal contact, professional organizations, and conference attendance as a means of connecting with other practitioners to share information? To what extent do gender, age, education levels, and experience levels impact this component of their PLNs?

4. To what extent do they report incorporating other technological and non-technological means to locate professionally relevant information? To what extent do gender, age, education levels, and experience levels impact this component of their PLNs?

5. What criteria do they use to determine expertise (trusted sources) especially as it relates to reaching out to others for advice? To what extent do gender, age, education levels, and experience levels impact their decisions about experts for inclusion in their PLN?

The quantitative and the qualitative responses to these major questions were analyzed and integrated with the result that several significant themes emerged.

The first theme that surfaced when analyzing the participant responses was the integral part non-formal learning plays in the daily life of these professionals. Non-formal leaning was described to the participants as all learning that occurred outside of formal classroom or online training that was requested or required by the employer. Nonformal learning could include emails, webinars, and meetings from professional groups. Using this definition, most of the participants described setting aside an average of three hours per week in their schedules for this purpose. They start their non-formal learning by receiving an automatic push of information via subscriptions to LinkedIn groups, professional organizations, and magazines that arrive in their daily email. Maria, a very busy Director in her company, explained that she schedules time in her calendar every week for non-formal learning in combination with her daily email feeds saying, "I get right into my mailbox in the morning and read electronic versions of key articles from Chief Learning Officer (CLO) Magazine, Talent Management, and Diversity Management. I try to schedule 30 minutes per week to read a chapter of a book. I try to read one book per month. I put it into my schedule to make sure this happens." Email has become an integral part of professionals' daily routine and many tools provide an automatic push of information via email based on a subscription. Participants described skimming through this information and using it as a starting point for further research. Since email plays such a significant role in daily professional life, leveraging a tool that is already an integral aspect of the work stream makes incorporating non-formal learning into daily work life relatively effortless.

The participants were also asked about how they approached learning is to help them meet the challenge of a new project for which they do not already have the knowledge and skills. In response to the question of what technological and non-technological means they use to locate professionally relevant information for a new pro- 
ject, most of these participants stated that they used a Google search as the technological starting point for their learning. After this first technological step, the second step was most often non-technological. The participants described locating books or reaching out to people in their personal network for assistance after their initial internet search. This makes clear the importance of having a strong network of trusted sources into which you tap for support.

The second major theme focused on the components of the participants' personal learning network including both technological and people resources. In terms of the technological tools the participants used to build their network of resources, their overall use of webinars and blogs appeared to be more highly valued and used than Twitter or Facebook. The participants described their reasons for using these tools as primarily a means to access information from experts on topics, and trends. These tools provide quick access to information and were used less as a means to develop connections to other people.

In addition to technological tools, a PLN can also include people resources. Therefore, the participants were asked how they use personal contact tools such as LinkedIn, professional organizations, and conferences to connect with other practitioners to share information. The combined results of statistical analysis and the interviews provided several interesting conclusions that can be drawn in response to this question. First, participants reported that professional organizations $(49 \%)$ conferences $(36 \%)$, and LinkedIn $(24 \%)$ were very important or vital to their non-formal learning. Since many of the participants were solicited using each of these methods it was not surprising that the participants placed a high value on these methods for connecting with others. Second, the reasons for using these tools was primarily to network, keep up-to-date on the latest information and trends in the industry as well as connect with experts in the field. These tools, while providing good examples of how others are working were primarily used as a means to develop a strong network of people on whom the participant could later call.

Participants' level of professional experience impacted their use of organizations, conferences, and LinkedIn. Less experienced professionals placed more value on professional organizations and conferences. More experienced participants placed an increased importance and participation on their personal network in LinkedIn. This tool, which is used to build and maintain communication with contacts, allows them to reach out to the professional network developed with experience and time. As the participants increased in experience, they were more likely to reach out to their network of connections that they had built through their years of experience rather than to experts sanctioned by professional organizations and their conferences.

The third theme that surfaced when analyzing the participant responses was how they evaluate experts (trusted sources) for inclusion and retention in their PLNs. Given the fast pace of knowledge creation, the quality of the network resources is critical to the overall value of the personal learning network. This dependency leads to the question of how we make our decisions about whether the information that this node (resource) provides is accurate and current. The ability to evaluate sources is critical to the individual having access to high quality information.
The participants were asked to describe by what criteria they evaluated experts for inclusion or exclusion from their PLN. The options they were given were formal education, organizational affiliation, contributions to blogs, of LinkedIn groups. They could also offer additional criteria that they used to supplement the provided criteria. The interview participants were asked an open-ended question about what factors and criteria the value of online content and the contributor.

The summary results from the survey indicated that respondents ranked the four survey criteria as the educational background, organization affiliation, blog, and LinkedIn as the order of importance when evaluating the expert. When adding in the results of the open-ended response for other contributing criteria, the importance of expert's experience in the field and previous writings were most often added to the list. When interviewed, the participants agreed that the expert's education and experience were the important criteria when making judgments about the contributor's expert status. In order to determine whether there were differences in the results that could be attributed to gender, age, education, or experience in the field, the responses were grouped together for further analysis.

In terms of differences among the participants' evaluation of experts grouped by education, their responses followed in line with their own educational background. The less educated groups tended to focus less on the expert's formal education and more on their experience and organizational support. The most educated group focused on the expert's formal education and publications in their evaluation. This result would certainly align with the investment that these groups made in their own education. In terms of differences among the participants' evaluation of experts grouped by experience, all of the groups ranked the expert's education, organizational support, blogs and then LinkedIn from highest to lowest in importance for their evaluation of experts. The entry-level participants, due to their inexperience in the profession were most concerned about gaining an understanding of who the experts are and getting access to good content. The mid-career group described previous writing and LinkedIn as key to their criteria for expert evaluation. The senior group was primarily focused on the expert's ability to communicate their knowledge to others through their writing. They also used the expert's direct, applicable experience above formal education in evaluation the expert. The results indicate that, as the participant gained experience in their field, they focused more on the quality and applicability of the information.

The results of this study also suggested that there are clear differences between the genders in how they approach constructing their personal learning networks. There was not a statistically significant difference between what the male and female participants chose as their primary means to access non-formal learning. But, the male participants reported spending statistically significantly more time on their non-formal learning than the female participants. Specifically, this result suggests that men are more willing and able to devote more time to their nonformal learning than women who may have conflicting requirements on their time. The actual reasons why women do not spend as much time on non-formal learning as the men did are not known and could be a topic for future study. Since there were a much smaller number of male participants (39) versus female participants (80), and it is 
not clear whether this proportion is with the profession, it is not possible to generalize from these findings.

In examining the primary components of the participants' personal learning network components, there were differences between the importance and participation in various tools based on the participant's gender. Men valued technological supports such as Twitter, blogs, social media more than women. By contrast, the female participants placed a greater importance on the tools that are more focused on personal contact and relationship development: professional organizations, conferences, LinkedIn, and webinars. The divergence from the literature that was discovered in this study was that the male participants placed a higher rating on social media. This may be due to the preference the male participants in this study had for technology over the female participants. The tools that the women valued more were those that have been traditionally associated with interpersonal interactions and network construction. During conferences and professional meetings, there is frequently time specifically set aside for connecting with others using small interest group sessions, "birds of a feather" lunches, and cocktail hours.

When examining if there was a difference between how men and women evaluated trusted sources (experts), their responses were consistent with their responses to their use of the tools in their PLNs. The male participants only rated the expert's participation in blogs, as more important than the female participants. In all of the other criteria, which were listed as personal contact tools in question three, the female participants rated them as more useful or important when evaluating experts. Since these are the tools that they found most useful, it makes sense that they would also use the same tools for evaluating experts. While using these tools for their own learning, they are exposed to a set of other professionals who also value and contribute using these tools. This shared experience establishes a bond and a baseline upon which to evaluate the other. Establishing personal connections has been shown to be more important for women than men and these are the tools that help to build them [18]. One caution about this approach is that the number and variety of the groups to which a person belongs determines the diversity of opinions to which they are exposed. Limiting the number of connections and groups to which one belongs can be a detriment to overall learning.

The participant's age also impacted the importance of various PLN components. The age-related differences in PLN construction demonstrated an inverse relationship between age and importance and participation in Web 2.0 tools. The older and more senior-level professionals seemed to depend more highly on personal contacts and participate in LinkedIn at a statistically significant greater level than the younger age groups. The 30-39 age group spent much more time dedicated to non-formal learning than the older groups presumably because they have much more to learn than their older peers. They also placed an overall greater importance on and participation in Web 2.0 tools than their older counterparts who come from another generation that may not value formal education as much as the older generation.

There was also a difference between the age groups in their evaluation of experts. The younger groups focused more on institutional support and formal education to help them make their decisions about who to follow. The older, more experienced participants tended to focus less on these formal credentials and, instead, focused on what the expert could demonstrate through their experience in the field and their publications.

\section{RECOMMENDATIONS}

This study uncovered information about how Training and Human Resource professionals currently approach their non-formal learning leading to significant implications for how to develop strategies to assist the other professionals in their work environments. The recommendations for practice can be broken into two different categories: individual learning and organizational learning. The first set of recommendations focuses on how individuals can harness the power of freely available tools to help them manage the great amount of information that they are faced with on a daily basis. The second set of recommendations addresses the ways in which training professionals can use the information from the study in modifying the corporate learning strategy to leverage the concepts of connectivism, personal learning networks, and non-formal learning.

The participants in this study reported spending one to three hour per week on non-formal learning which they receive primarily automatically through email. They skim the information in the group emails and use trends or work-related topics as a springboard to manually search for more information. This implies that the participants have integrated their non-formal learning into their everyday work stream. The Training group can use this approach to send small bites of information (micro-learning) to their target learners using emails. The prolific use of email for non-formal learning implies that the study participants did not talk about sharing the information that they learned with other members in their network. This was primarily a solitary task for personal improvement. Since is not possible for every individual to learn everything there is to know [11], learning must happen through the sharing of experiences. Not only is the participant dependent on other's learning, but the participant has an obligation to contribute their own learning back into their personal learning network. Their network could benefit from the participant's sharing information by forwarding this information through email, reflections in a blog post, or tweets to pass along the links. Sharing information like this might start a conversation about the topic and could improve the participant's and others in their network's understanding of the topic. This could be the springboard for a larger improvement initiative within the organization. The lack of sharing represented in this study describes a huge loss in opportunity for learning in the network.

For specific task-oriented learning, participants described using Google as their first source of information. If, however, the participant needs to access propriety knowledge within the corporation, a Google search will not work. A search within the corporate intranet may help the participant locate the information required but only if the contents have been adequately tagged. In order to make the intranet really usable for learning, there must be strong institutional and structural support for information sharing across departments. Frequently, the various departments in large corporations are silo-ed. While each department may have built methods for sharing best practices, there may not be a formalized mechanism for shar- 
ing information across departments. Instead, the individual must rely on their individual network of people contacts. Relying solely on this internal network of people may make locating useful and timely information virtually impossible. This represents a huge opportunity for the corporation to provide an internal mechanism for a centralized means of sharing information across all departments. Constructing internal wikis and social networking sites will help to break down the information barriers.

None of the participants in this study talked about nonformal learning initiatives at their work. If there were such initiatives going on at their companies, these are the people who would or should be involved in implementing them. There seems to be a lack of connection between the amount of non-formal learning that they do on their own and what their learners must be doing to learn for their own jobs. Only one person mentioned thinking about electronic performance support systems (EPSS) and that was someone who was contacted at the Performance Support conference.

Age, gender, education, and experience all have impacts on how people use non-formal learning and so it makes a difference who the workers are when designing new initiatives. Training groups often perform a learner analysis when designing new programs. This should hold true for non-formal learning support initiatives. The older and more experienced the participant was, the more likely they were to depend on personal connections built over a career rather than turning to Web 2.0 tools and people that they do not know professionally. What, this also means also is that they themselves are not as willing to contribute to the overall network. As a result, the knowledge that they have built over a career is not being shared with the wider network. This causes a lot of unnecessary effort spent on learning that could have been gained from experienced participants. In this study, the participants valued webinars and blogs over Twitter and social media as technological components in their PLN. All of these factors play into what the learners will initially be more comfortable with and, as a result, more willing to incorporate into their non-formal learning. There is value in the other available tools. So, in order to include them into a nonformal learning initiative, the training group must also include a fair amount of change management into any new initiative for it to be successful.

The faster that new information is created, the more important it is to be able to reach out to others for help. But with this dependency comes an increasing necessity to trust the sources of this information. Tools like Amazon product ratings, Angie's List, and Yelp help people validate products and service providers in an open online world. To validate experts and their claims, the study participants also used a "trust but verify" approach. They frequently rely on name recognition and the connections of those easily recognizable people. The name recognition often comes from writing and speaking engagements. If the expert is not easily recognizable, the next step is to verify their education and experience using their online presence on sites like LinkedIn. We are more dependent on the out-spoken other who is willing to provide feedback on posts to guide the evaluation of a blog post. The challenge of this age is the abundance of information and the need to quickly and effectively evaluate it and the source.
A personalized learning dashboard will help to provide this overview. Freely available tools like HootSuite provide a one-stop aggregator for social network sites, Twitter, and RSS feeds that provides an overview of what's going on in the defined area of interest. HootSuite allows the user to set up multiple tabs that can be used to group feeds according to a set of interests. Tools like Pinterest can be used to create boards that are essentially personalized digital magazine pages that update as the linked pages update. Reviewing each Pinterest board gives a snapshot of all of the changes to the linked sites that are related to a topic. Subscribing to others' Pinterest boards expand a user's network to include learning from what others have found. Other organizing tools like EverNote can be used to compile a list of links to sites for later reference. Tools that can be used to easily combine, remix, and track content will be increasingly important to personal learning networks as the pace of content creation increases over the next several years.

The issues related to the speed of knowledge creation also affect how learning happens in the organization. The cost of designing and delivering formal training programs as well as the cost of removing the employee from the work place in order to attend a training course that only meets at most $20 \%$ of the worker's learning needs have given rise to an increase in interest in a new and better solution.

Human Resources and Training groups need to help shift the idea of workplace learning away from comprised of only formal training program to becoming a learning organization where learning is embedded in the work processes [12]. Creating a learning culture in the organization has a strongly positive relationship with integrating new technological advances into the daily work activities [13]. Employees working in organizations that encourage personal learning (non-formal) become better able to adapt to the constant changes and demands made on them in the workplace [14].

Knowledge is no longer something that can be acquired. It is something that is distributed throughout a network [11]. As a result, the quantity and quality of network connections are critical. Since more experienced individuals have constructed a deep network over their years of work experience, the older employees contribute greatly to the organization through their own network. Companies can help learners to create more connections to information and experiences across boundaries by using social media sites [19]. Since learning happens through the network while accomplishing work, leveraging social media provides the supports for working with a much larger and diverse group. The shift in non-formal learning toward the cultivation of a personal learning network is a fundamental principle of connectivist learning theory.

It is impossible for the Training organization to keep up with the fast pace of knowledge creation in the workplace through the delivery of formal training programs. Instead of focusing on the content and behaviorist learning objectives, the HR and Training departments should instead be focusing on the learning process [20]. Instead of continuing with the traditional behaviorist or constructivist oriented instructional design models, these groups should consider incorporating more of the connectivist theory into their instructional designs. Connectivism includes some important aspects of andragogy such as the assumption 
that the adult learner is has the ability and self-motivation to control their own learning [5].

One of the key characteristics of the connectivist theory is that learning happens through the creation of learning artifacts and that these artifacts should persist beyond the course. Instead of creating closed courses, using predefined practice exercises with specific tasks and outcomes, a formal course should allow for learners to create artifacts like Wikipedia entries, YouTube videos, and blog posts. These artifacts can be incorporated into an organizational learning support system. An organizational support system in which all of the groups within the organization share the burden of corporate learning, changes the learning dynamic from a centralized control system to a decentralized model. It leverages the knowledge of the entire organization into a deeper and richer knowledge base.

Another key aspect of connectivism that the HR and Training departments should be focusing on is helping learners to construct a strong network of resources. One of the most important aspects of massive open online courses (MOOCs) is the connections to others that are made by reading and responding to others' artifacts. Instead of using closed instructor-led training courses, the formal programs could incorporate some of the design principles of MOOCs. In MOOCs, different experts are responsible for gathering content sources for different topics rather than one instructor. This access to company-wide experts would help the new employee gain access to the leaders within the organization. Creating and commenting on artifacts as part of the course helps the learners to connect with each other. The construction of this company-wide network will help the learners after they leave the formal course. When they have a learning need in their daily work, they will have a rich network of resources on which they can call. A new approach to learning support is more appropriate for the $80 \%$ of learning that is primarily nonformal. Instead of being the owners of all learning, corporate HR and training groups should become the evangelists in cultivating a learning organization. These groups should spend more time and energy trying to use low or no cost methods to harness the knowledge of their staff. The workers are already using tools and resources in their personal learning networks. Leveraging their PLNs within the corporate learning strategy will provide a stronger learning structure.

Just as with designing and developing formal learning programs, one of the first steps for non-formal programs should also be to examine the learner population. Given the results of this study, several key employee characteristics impact the success and acceptance of any new initiatives. First, the employee's gender impacts on their willingness to use impersonal or personal tools. Second, the employee's age impacts on their willingness to use technological supports for learning. Finally, the more educated the participant was, the more he or she valued the expert's education in their evaluation and, by extension valued less well-educated experts less. Taking all of these characteristics into consideration and offering options that will help each of the populations would help to ensure greater program and learner success.

The mission of the HR and training groups should change and expand from meeting only $20 \%$ of the corporate learning needs to implementing new approaches that meet $100 \%$ of the learning need. In addition to changing the approach to formal learning, these groups should be the ones constructing a framework for and implementing an electronic performance support system (EPSS) that meets the non-formal learning needs.

An electronic performance support system is a tool that stores small amounts of learning content, sometimes called learnlets or microlearning, that provide just enough content within the context to help the user complete the task at hand. In order for an EPSS to be effective, the user must be able to easily access only relevant content that is integrated into the work stream. To meet the learning at their moment of need, the learnlets need to be served up within the context and based on the user's role. This requires a significant understanding of all of the roles and their responsibilities.

In this study, the workers listed two primary instigators for their non-formal learning; keeping up with trends and new project or task-specific learning. For on-going learning to keep up with changes in their work, they described spending a mean of three hours per week primarily using email as the aggregator for updates. To leverage this approach, the EPSS must be able to provide updates to the worker on a subscription basis to their email. The use of email updates helps make the EPSS a natural fit within their daily lives. For new learning that is task-oriented, the study participants described using a Google or Wikipedia search as their first step for learning. This approach to learning presents a challenge for corporate leaning since much of the content that users need to access is proprietary and only accessible from internal systems behind the firewall. The EPSS must have an easily accessible and highly-usable search system that allows the worker to enter a search keyword or question to directly access the content links and wiki pages that are appropriate for this question.

While the ownership of the EPSS would be in the HR or Training department, the primary responsibility for content creation should be spread throughout the entire organization. The content can come from the artifacts from formal training programs as described above. But, it should also come from all members of the organization. They can use all of the Web 2.0 tools to create wiki pages, blogs, tweets, vblogs, write joint articles, present as a group at conferences, and videos using a YouTube or TedTalk-like format that can all be tagged and stored in the centralized EPSS.

The Training group should become the content curators. This group should ensure that the content is tagged correctly for searching. They can also be the central organizers and creators of "just enough" training modules sometimes referred to as micro learning or "learning snacks." They can organize Google hangouts for collaborative learning to replace the "lunch and learn" programs. A Google hangout would provide workers to gather online to discuss a topic that could be recorded with the recording stored in the EPSS.

The following is a summary of the recommendations for constructing a personal learning network and modifications for the HRD and training departments' approach to the learning strategy to meet organizational needs:

Personal learning network construction recommendations:

- Incorporate Twitter, social media and blogs as integral parts of personal learning. 
- Create new, timely, and relevant content to enhance social ties.

- Use social bookmarking to access and share relevant information with the network.

- Create dashboards to aggregate content from various sources based on topics of interest.

Organizational learning recommendations:

- Formal learning strategy

- Develop courses only for critical procedures and for the appropriate moments of need: when first learning about a topic and when learning more about a topic

- Use connectivist principles in formal learning courses to encourage students to create artifacts that can be stored and accessed from the intranet, corporate wiki, or electronic performance support system (EPSS).

- Leverage experts as facilitators of course topics, possibly in MOOCs rather than only as subject matter experts.

○ Develop small "just-enough" training learnlets, especially using a video format, that can be incorporated into a learning on demand system behind the firewall that can be tagged and searched using a Google-like interface.

- Non-formal learning strategy

o Leverage the learners' approach to non-formal learning: email for on-going learning and Google searches for project-based learning.

- Develop a wiki that is curated by the Training or HRD group and added to and updated by the entire organization.

- Encourage the development of communities of practice across all departments and internal organizations to break down the silos of information present in many corporations.

\section{CONCLUSION}

This study investigated the non-formal side of connectivist learning by examining how one set of professionals develop their personal learning networks to help them stay up-to-date in their profession. Over the years, there has been a significant amount of research focused on identifying how best to develop formal workplace learning programs. Although the idea that up to $80 \%$ of learning in the workplace occurs non-formally or informally is not new, Training and Human Resource groups do not place an equivalent percentage of their resources towards supporting programs that help to develop a learning culture.

Since George Siemens first described connectivist learning theory in 2005 , the majority of the research to examine this theory has also been focused on the formal side of the theory that is present in MOOCs. Very little research has investigated the non-formal side of connectivist learning that occurs on a daily basis through the cultivation of a personal learning network. In studying a population whose careers have focused on helping others to learn and are pre-disposed to continuous learning, the researcher hoped to understand how professionals currently approach their own learning. By understanding how this population uses continuous learning, the researcher was able to draw some conclusions and to make recommenda- tions for future changes to the overall corporate learning strategy to leverage the non-formal learning that is already occurring through the professionals' PLNs.

The results of this research will be important for any adult educational activity, but may be particularly useful for corporate education and training groups that must meet the demands of providing learning support for employees in a rapidly changing world. Using this information will help organizations to determine what options are available for employees that could augment their efforts. This would then allow them to better align their resources in support of these outside sources.

\section{REFERENCES}

[1] Czarnowsky, M., \& Paradise, A. (2008). Tapping the potential of informal learning. In J. Edlund-Braun \& M. Soyars (Eds.), Alexandria, VA: American Society for Training and Development.

[2] Jubas, K., \& Butterwick, S. (2008). Hard/soft, formal/informal, work/learning: Tenuous/persistent binaries in the knowledgebased society. Journal of Workplace Learning, 20(7/8), 514-525. http://dx.doi.org/10.1108/13665620810900337

[3] Miller, L. (2012). State of the industry 2012. In G. Saltzman (Ed.), ASTD's Annual Review of Workplace Learning and Development Data. Alexandria, VA: American Society for Training and Development.

[4] Siemens, G. (2005b, August 14, 2011). Connectivism: Learning as network creation. Retrieved from http://www.elearnspace.org/ Articles/networks.htm

[5] Knowles, M. S., Holton, E. F., \& Swanson, R. A. (1998). The adult learner: The definitive classic in adult education and human resource development (5th ed.). Woburn, MA: ButterworthHeinemann.

[6] Siemens, G. (2006b). Knowing knowledge (pp. 168). Retrieved from http://books.google.com/books?id=Pj41TomgKXYC\&lpg= PR5\&ots=WskDNtwViL\&dq=george \%20siemens\%20knowing\% 20knowledge\&lr\&pg $=$ PR5 $\# \mathrm{v}=$ onepage\& $\mathrm{q} \& \mathrm{f}=$ false

[7] Pettenati, M. C., \& Cigognini, M. E. (2007). Social networking theories and tools to support connectivist learning activities. International Journal of Web Based Learning and Teaching Technologies, 2(3), 42-60. http://dx.doi.org/10.4018/jwltt.2007 $\underline{070103}$

[8] Siemens, G. (2004b). Connectivism: A learning theory for the digital age Retrieved from http://www.elearnspace.org/Articles/ connectivism.htm

[9] Bauer, W. (2010). Your personal learning network. Music Educators Journal, 97(2), 37-42. http://dx.doi.org/10.1177/0027 432110386383

[10] Fredrick, K. (2010). Resource roundup for your personal learning network. School Library Monthly, XXVII(1), 38-39.

[11] Siemens, G. (2005a). Connectivism: Learning as network creation. Retrieved from http://www.elearnspace.org/Articles/networks.htm

[12] Vaughan, K. (2008). Workplace learning: A literature review. Auckland, NZ: The New Zealand Engineering Food \& Manufacturing Industry Training Organisation.

[13] Reardon, R. (2010). The impact of learning culture on worker response to new technology. Journal of Workplace Learning, 22(4), 201-210. http://dx.doi.org/10.1108/13665621011040662

[14] Panari, C., Guglielmi, D., Simbula, S., \& Depolo, M. (2010). Can an opportunity to learn at work reduce stress? A revisitation of the job demand-control model. Journal of Workplace Learning, 22(3), 166-179. http://dx.doi.org/10.1108/13665621011028611

[15] Creswell, J. W. (2009). Research design: Qualitative, quantitative, and mixed methods approaches (3rd ed.). Thousand Oaks, CA: Sage.

[16] Creswell, J. W. (2008). Educational research: Planning, conducting, and evaluating quantitative and qualitative research (3rd ed.). Upper Saddle River, N.J.: Pearson/Merrill Prentice Hall.

[17] Creswell, J. W. (2007). Qualitative inquiry and research design: Choosing among five approaches (2nd ed.). Thousand Oaks, CA: Sage Publications. 
PAPER

The Construction of Personal Learning Networks to Support Non-Formal WorkPlace Learning of...

[18] Hargittai, E. (2007). Whose space? Differences among users and non-users of social network sites. Journal of Computer-mediated Communication, 13(1), 19. $\quad$ http://dx.doi.org/10.1111/j.10836101.2007.00396.x

[19] [19] Chen, B., \& Bryer, T. (2012). Investigating instructional strategies for using social media in formal and informal learning. The International Review of Research in Open and Distance Learning, 13(1), 87-104.

[20] Sahin, M. C. (2009). Instructional design principles for $21 \mathrm{st}$ century learning skills. Procedia Social and Behavioral Sciences, 1, 1464-1468. http://dx.doi.org/10.1016/j.sbspro.2009.01.258

\section{AUTHOR}

C. A. Manning, $\mathbf{P h D}$ is with the University of Massachusetts, Boston, Boston, MA 02125 USA (e-mail: Christin.Manning@umb.edu) and Brandeis University, Waltham, MA 02453 USA.

This work was supported in part by Lesley University. Manuscript received 07 January 2015. Published as resubmitted by the author 02 June 2015 . 